\title{
ANIMAIS, HOMENS E SENSAÇÕES SEGUNDO DESCARTES
}

\author{
Ethel Menezes Rocha*
}

RESUMO $O$ objetivo central deste artigo é examinar em que sentido Descartes está efetivamente comprometido com a tese forte de que, no caso dos animais não-humanos, não há sensação propriamente dita, mas apenas movimentos da matéria, e em que sentido os argumentos em favor dessa tese tornam problemática a tese, com a qual Descartes também se diz comprometido, de que todos os animais humanos têm sensações.

Palavras-chave Sensações, máquinas, animais

ABSTRACT My main purpose in this article is to analyze the extent to which Descartes is indeed commited to with the strong claim that, in the case of non-human animals, there are no sensations, but rather only movements of matter, and analyze to what extent his arguments in favor of this claim makes problematic the other claim to which he also seems to be committed, that is, that all human animals have sensations.

Key-words Sensations, Machines, Animals

O objetivo deste texto é, a partir da consideração da tese cartesiana da distinção real entre corpo e alma e da tese cartesiana de que as sensações,

Professora da Universidade Federal do Rio de Janeiro, IFCS, Departamento de Filosofia. Artigo recebido em junho de 2004 e aprovado em outubro de 2004. (ethelmrocha@uol.com.br)

KRITERION, Belo Horizonte, $n^{0}$ 110, Dez/2004, p. 350-364 
embora não sejam modos puros do pensamento, são modos do composto corpo e alma que envolvem, portanto, o corpo e o pensamento, apontar para o que parece ser um embaraço para a economia da metafísica cartesiana, a saber, o fato de Descartes sustentar duas teses aparentemente conflitantes: 1) a de que, por ser possível explicar todo comportamento do animal não-humano excluindo pensamento ou consciência deste, essa é a explicação correta; e 2) a de que, embora para o caso dos outros homens, que não aquele referido pelo termo "eu”, a princípio, essa explicação também seja possível, essa não é a explicação correta. Apesar de alguns intérpretes de Descartes, partindo de algumas passagens de sua obra, pretenderem que ele de fato não defende a tese forte de que os animais são meros autômatos mecânicos, desprovidos de pensamento e de experiências sensoriais, neste artigo tenciono mostrar que não só Descartes defende explicitamente essa tese fornecendo argumentos, mas, mais ainda, que, a julgar por esses mesmos argumentos, é pelo menos embaraçoso que ele não conclua o mesmo com relação aos outros homens que, sendo numericamente distintos de mim, sem que haja qualquer garantia do contrário, podem ser também qualitativamente distintos de mim. Em outras palavras, trata-se de mostrar em que sentido Descartes está efetivamente comprometido com a tese mais forte de que no caso dos animais não-humanos não há sensação propriamente dita, mas apenas movimentos da matéria, e em que sentido os argumentos em favor dessa tese tornam problemática a tese, com a qual Descartes também se diz comprometido, de que todos os animais humanos têm sensações.

A tese de que os animais são meros autômatos é sustentada por Descartes basicamente em oposição à visão escolástica segundo a qual toda criatura viva é dotada de alma, o que implica numa hierarquia de faculdades, muitas vezes referida como as várias partes da alma — vegetativa, sensitiva e racional que seriam responsáveis por todo comportamento das criaturas vivas sendo, no caso dos animais não-humanos, a parte sensitiva da alma a que apreenderia as sensações. Segundo Descartes, essa explicação faz um apelo excessivo à alma para a explicação dos comportamentos tanto dos homens (seus movimentos puramente fisiológicos) quanto dos animais não-humanos. Descartes insiste na tese segundo a qual tanto o comportamento corporal do homem quanto o comportamento do animal podem ser explicados em termos puramente mecânicos e, se é assim, não é necessário recorrer a conceitos como alma, forma substancial etc. ${ }^{1}$

1 Note-se que Descartes evita usar o termo "animal" preferindo "besta" ou "bruto", provavelmente porque o termo "animal" sugere imediatamente vestígios da idéia escolástica de que todo ser vivo é dotado de alma, idéia da qual Descartes pretende se afastar. 
Neste artigo pretendo reconstruir a argumentação de Descartes mostrando serem essenciais os seguintes passos: 1) assumir a tese da distinção real corpo e alma e da união substancial do corpo com a alma no homem; 2) mostrar que é com recurso à tese da perfeição divina que Descartes prova que os animais podem ser meros autômatos mecânicos, isto é, que ele demonstra ser plausível a tese de que qualquer comportamento do animal não-humano pode ser explicado sem recurso a um suposto pensamento ou consciência por parte do animal - como veremos, para tanto, ficará claro que Descartes entende que todo pensamento tem sempre uma estrutura proposicional e, portanto, supõe a capacidade de expressão discursiva, o que implica que Descartes entenda sentir e ter uma idéia de que sente como equivalentes entre si; 3) finalmente, mostrar que Descartes, recorrendo ao princípio de que "a natureza sempre age pelos meios mais simples e fáceis" ${ }^{2}$, demonstra que, se é possível explicar todo o comportamento dos animais não-humanos e certos comportamentos humanos sem recurso à razão ou consciência, e, portanto, se o recurso ao que seria a parte vegetativa ou sensitiva da alma é supérfluo e desnecessário, então, deve-se concluir a tese mais forte, a saber, que os animais não-humanos efetivamente não pensam e, mais que isso, não têm consciência sensorial e, portanto, por exemplo, não sofrem. Com essa reconstrução da argumentação cartesiana, pretendo ainda apontar para duas dificuldades que daí decorrem, a saber, que, se a tese da ausência de pensamento nos animais não-humanos decorre do fato de estes não terem linguagem, Descartes terá que identificar sensação com idéia de sensação, do contrário, as expressões naturais (tais como choro, gemido etc) dos animais não-humanos expressariam sensações, o que Descartes não pode aceitar. Entretanto, visto que esse filósofo efetivamente identifica sensação com idéia de sensação, e visto que o modo como os outros homens manifestam espontaneamente suas sensações é através de expressões naturais como a dos animais não-humanos, então dever-se-ia concluir para o caso dos humanos o mesmo que para os não-humanos: suas expressões naturais não expressam sensações, mas apenas movimentos corpóreos.

É sabido que a ontologia cartesiana só admite dois tipos de substância criada: a alma (ou substância pensante) e o corpo (substância extensa), cujas naturezas são realmente distintas. Visto que, quando duas coisas são realmente distintas, segundo a terminologia cartesiana, elas têm propriedades que são mutuamente incompatíveis, uma coisa extensa é não-pensante, e uma coisa

2 Tratado sobre o homem, (AT XI, p. 201,) no qual o contexto de discussão é justamente o da não-necessidade do recurso a uma alma vegetativa ou sensitiva para a explicação do comportamento do que seria um homem-máquina. 
pensante é não-extensa. Uma substância pensante pura seria dotada apenas de entendimento e vontade (que são os gêneros do pensamento segundo Descartes), e uma criatura extensa, ao contrário, não teria qualquer experiência e funcionaria apenas como um autômato mecânico. A experiência sensorial, por outro lado, que não pode ser atribuída nem à mente nem ao corpo, se tomados isoladamente, consistiria num tipo distinto de fenômeno que suporia a união substancial (em oposição a uma mera justaposição) do corpo com a alma. A princípio, portanto, a experiência sensorial que não é parte da natureza de uma substância pensante nem da natureza de uma substância extensa pertenceria ao eu enquanto substância pensante apenas na medida em que essa substância pensante é dotada de um corpo e, por isso mesmo, é um ser humano. Assim sendo, para o caso do homem, em virtude do fato de este ter experiências sensoriais, Descartes terá que introduzir a tese da união substancial, pois, nas palavras desse filósofo, " [...] com efeito, todos esses sentimentos de fome, de sede, de dor, etc., nada são exceto maneiras confusas de pensar, que provêm e dependem da união e como que da mistura entre a mente e o corpo".

Dessa forma, as sensações envolveriam, por um lado, o pensamento, o que é claro, por exemplo, ao atentarmos para a Segunda Meditação, quando, ao explicitar o que é uma coisa pensante, Descartes afirma: "É uma coisa que duvida, compreende, concebe, afirma, nega, quer, não quer, e que também imagina e sente". Evidentemente, o fato de sentir (e imaginar) aparecerem, na enumeração dos modos do pensamento, como que anexados através de um termo (o termo "também") sugere uma diferença desses modos com relação aos outros atos mentais enumerados. Essa diferença será tratada mais tarde por Descartes, quando mostrará que, em um certo sentido, as sensações são modos mistos, obscuros e confusos que envolvem, portanto, também o corpo, e, dessa forma, são modos do composto corpo e alma. Assim, estritamente falando, as sensações não são modos do pensamento puro. Se admitirmos, porém, como Descartes, a tese da distinção real entre o corpo e a alma e suas consequiências, então admitiremos também que apenas a alma pode pensar. E, se é assim, apenas parte das sensações pode ser chamada de pensamento, sendo a outra parte resultante do elemento corpóreo da composição. Como afirma Descartes em uma carta a Gibieuf, "sensações pertencem à alma, porque são modos de pensar; entretanto pertencem à alma apenas na medida em que esta está unida ao corpo".

Além de estabelecer que apenas parte das sensações se deve ao fato de que o composto pensa, Descartes tem que mostrar a tese mais forte de que só porque o composto pensa ele tem experiências sensoriais. Em suas respostas às Sextas objeções, o filósofo diferencia três graus de sensação. Segundo o 
que afirma, devemos distinguir três graus de resposta sensorial. O primeiro se limita ao estímulo imediato dos órgãos corpóreos, ou seja, à afecção imediata de um órgão corpóreo por um objeto externo; o segundo grau de sensação consiste em qualquer resultado mental imediato dessa afecção, tal como, a percepção da dor, da fome, do calor, da cor etc; e o terceiro consiste nos juízos que fazemos a partir do movimento nos órgãos corpóreos. O primeiro grau de sensação seria, portanto, puramente mecânico, não consistindo, em sensação propriamente dita, mas sim apenas no movimento de partículas dos órgãos e na mudança de forma e posição que resulta desse movimento. Esse grau de sensação Descartes admite ser comum a todo animal, seja humano ou não. O segundo, na medida em que se trata de uma percepção, envolveria consciência e seria resultante do fato de que a mente está de tal modo intimamente unida ao corpo que é afetada pelos movimentos que ocorrem nele; e o terceiro seria pensamento puro e consistiria no juízo que fazemos, resultante do fato de sermos afetados por uma sensação e dependente apenas do intelecto.

A tese de Descartes acerca da impossibilidade de atribuição de sensações aos animais é, portanto, bastante clara: o que ele nega aos animais é o segundo e o terceiro graus de sensação, isto é, nega a consciência da sensação e o juízo que envolve a sensação, o que implica na negação do sofrimento e da expressão deste, mas não nega o primeiro grau de sensação, que envolve apenas estímulos e movimentos corpóreos e uma possível expressão desses movimentos. Isso é claro quando na mesma resposta às Sextas objeções ele declara:

[...] aqueles que me objetam afirmam que não acreditam que o modo como os animais funcionam possa ser explicado por meios mecânicos sem recurso a qualquer sensação, vida ou alma. Tomo isso como querendo dizer sem recurso a pensamento; pois aceito que os animais têm o que comumente se chama de "vida" e uma alma corpórea e sensação orgânica.

A tese de Descartes de que os animais são meros autômatos se baseia, num primeiro momento, na tese de que é possível explicar o comportamento do animal por analogia ao comportamento do corpo humano que, por sua vez, pode ser explicado por analogia ao funcionamento de uma máquina complexa o bastante que torne possível a imitação de certo tipo de comportamento humano. Sendo assim, o primeiro passo da argumentação cartesiana será mostrar que o funcionamento do corpo humano pode ser explicado por recurso a movimentos puramente fisiológicos sem recurso a razão, ou pensamento.

É no Discurso sobre o método, Parte V, que esse argumento inicial é melhor exposto. Essa exposição é introduzida através de um resumo das idéias demonstradas em um livro anteriormente escrito, mas não publicado, o Tratado sobre o homem, acerca da hipótese de um homem-máquina, a saber, a hipótese 
de que um homem seja criado por Deus inicialmente apenas como corpo, sem alma. Apesar de esse homem-máquina não ter qualquer faculdade da alma, Deus, entretanto, teria posto nele tudo o que fosse necessário para andar, comer, respirar e, "na verdade, imitar todas as nossas funções que podemos imaginar proceder da matéria e depender apenas da disposição de nosso órgãos". Descartes justifica essa hipótese afirmando, ainda,

[...] de nenhuma maneira isso parecerá estranho àqueles que, sabendo quantos autômatos diferentes ou máquinas móveis pode engendrar a indústria humana [...] considerando o corpo animal como uma máquina que, tendo sido obra das mãos de Deus, é sem comparação possível mais bem arrumada e tem em si movimentos mais admiráveis do que qualquer daquelas que os homens possam inventar.

Nesse sentido, conclui Descartes que as funções que esse corpo-máquina criado por um ser perfeitíssimo poderia ter seriam "todas aquelas que pode haver em nós sem que o saibamos e, portanto, sem que nossa alma dê qualquer contribuição, isto é, esta parte distinta do corpo cuja função consiste unicamente em pensar."

Num segundo momento da argumentação, Descartes pretende concluir que uma explicação semelhante à do funcionamento do homem-máquina é plausível no que diz respeito ao comportamento animal. Conforme o filósofo, se existissem máquinas com peças semelhantes aos órgãos e com a forma exterior de um animal irracional, não haveria meios para distingui-la do animal, o que implica que todo comportamento animal pode ser explicado como se explica o funcionamento do corpo que não é dotado de alma, ou o funcionamento de uma máquina. Em outras palavras, Descartes deseja mostrar que a explicação de fenômenos que não exigem a intervenção da vontade e, por isso mesmo, do pensamento, como, por exemplo, a respiração, o fluxo do sangue e a proteção instintiva de agressões físicas, é semelhante à explicação de comportamentos animais não-humanos, tais como a fuga da ovelha diante de um lobo. A estranheza dessa tese é notada por Arnauld, em sua objeção:

[...] à primeira vista parece inacreditável que possa ocorrer, sem a ajuda de qualquer alma, que a luz refletida a partir do corpo de um lobo nos olhos de uma ovelha movimente as fibras minúsculas dos nervos óticos e que ao alcançar o cérebro o movimento espalhe os espíritos animais através dos nervos de modo necessário a ocasionar a fuga da ovelha.

O principal argumento de Descartes para demonstrar a diferença entre a máquina e o homem, por um lado, e a semelhança entre a máquina e o animal não-humano, por outro, consiste na incapacidade tanto da máquina quanto do animal não-humano de usarem uma linguagem. Prosseguindo no texto do 
Discurso, Parte V, Descartes afirma que, ao contrário do caso dos animais, se existissem máquinas o máximo possível (tanto quanto moralmente possível) semelhantes ao homem, haveria sempre dois meios muito eficazes para distingui-los, dentre os quais o primeiro é que as máquinas, diferentemente dos homens, jamais seriam capazes de empregar palavras para transmitir seus pensamentos.

[...] contaríamos com dois meios muito certos de reconhecer que nem por isso elas eram homens verdadeiros. O primeiro desses meios está em que jamais seriam capazes de empregar palavras ou outros sinais, compondo-os, como nós fazemos, para transmitir aos outros nossos pensamentos.

Do mesmo modo, utilizando quase as mesmas palavras, Descartes, em carta a Henry More, ${ }^{3}$ explica que o que demonstra que os animais não-humanos são substâncias apenas corpóreas, sem pensamento ou razão, é o fato de que não são capazes de, através de voz ou outro sinal qualquer, expressar seus pensamentos,

[...] o argumento principal que pode nos convencer de que os animais não têm razão é que [...] nunca foi observado que qualquer animal tenha alcançado um tal grau de perfeição de modo a ser capaz de nos indicar por voz, ou por outros sinais, alguma coisa que pudesse ser referida como pensamento apenas, em oposição a movimento meramente natural.

Daí pode-se concluir que, para Descartes, a diferença entre os animais nãohumanos e as máquinas, por um lado, e os homens, por outro, reside na incapacidade daqueles de reunir várias palavras ao mesmo tempo e de compor com elas um discurso pelo qual façam compreender seus pensamentos. Sendo assim, podemos afirmar que, segundo Descartes, o que prova que os animais não pensam é o fato de que não falam. Isso é confirmado pelo que ele afirma nessa mesma carta a Henry More:

[..] pois a palavra é o único signo e a única marca certa da presença de pensamento escondida e envolta no corpo; ora, todo homem, seja o mais tolo e mais estúpido, mesmo aqueles que não têm os órgãos da fala, faz uso de sinais, enquanto os brutos nunca fazem qualquer coisa desse tipo; o que pode ser tomado pela verdadeira distinção entre o homem e o bruto.

Ao argumentar, portanto, que o animal não tem pensamento, como vimos, Descartes recorre ao fato de que o animal não é capaz de se expressar 
discursivamente, o que sugere que o pensamento, para esse filósofo, tem uma estrutura proposicional. Essa tese, na verdade, já é anunciada na Terceira Meditação, quando Descartes se propõe a dividir em gêneros os pensamentos. Essa divisão consiste em dois gêneros: as idéias, que são como imagens de coisas, e os outros, que podem ser volições ou juízos. Os gêneros de pensamento, portanto, são, basicamente, as idéias pelas quais represento, isto é, exibo um conteúdo ao meu espírito, e os outros, através dos quais acrescento uma ação mental a esse conteúdo exibido em meu espírito. Essa divisão sugere, por sua vez, que idéias são conteúdos proposicionais presentes em qualquer pensamento, e que o pensamento tem, de um modo geral, uma estrutura proposicional que pode envolver apenas a exibição de conteúdo proposicional (isto é, aquilo sobre o que se está pensando) ou, além disso, uma atitude mental relativa a esse conteúdo (de dúvida, medo, assentimento, desejo, rejeição etc). Para Descartes, o pensamento tem essa estrutura proposicional que envolve um conteúdo proposicional e uma atitude proposicional. Isso fica claro também se considerarmos que ele, ao explicar, na Segunda Meditação, o que é uma coisa que pensa, recorre a atitudes mentais que envolvem um conteúdo proposicional ao qual se aplica. Uma coisa que pensa é uma coisa que concebe (ou seja, que exibe no espírito, mesmo que confusamente, uma situação, como podendo ser o caso), que duvida (ou melhor, hesita quanto a ser ou não o caso de uma situação expressa, ainda que de forma confusa, por uma idéia), que afirma (isto é, que afirma ser o caso uma situação expressa, mesmo que confusamente, por uma idéia), que nega (ou seja, que afirma não ser o caso uma situação expressa, ainda que confusamente, por uma idéia) etc. Assim, a partir dessa divisão do pensamento em seus gêneros, Descartes tem que admitir que mesmo as idéias têm uma estrutura proposicional. Se é sobre idéias que as atitudes mentais incidem, o conteúdo da idéia não pode ser um objeto mental, mas, em vez disso, deve ser uma proposição, visto não ser o caso que desejamos, afirmamos, negamos, queremos ou não queremos um objeto mental ou uma imagem das coisas, mas sim, ao contrário, as próprias coisas que são expressas em proposições. A idéia consiste na exibição no espírito de um conteúdo proposicional, na medida em que se constitue na exibição de uma situação possível. Por outro lado, qualquer atitude mental que é acrescida a uma idéia também terá uma estrutura proposicional, na medida em que consiste em uma tomada de posição diante daquilo sobre o que se está pensando, o que implica que, para toda atitude mental, há, por assim dizer, uma força ilocucionária correspondente que é o que determina o tipo de ato mental envolvido e que é expresso por palavras (ou gestos, ou olhares) de uma língua. Sendo assim, efetivamente, a capacidade de uso da linguagem é condição para que haja 
pensamento em qualquer um de seus gêneros. A idéia, portanto, tem uma estrutura proposicional na medida em que exibe uma situação possível, e as atitudes mentais têm uma estrutura proposicional na medida em que projetam de uma determinada maneira, no mundo, essa proposição que expressa uma situação possível (hesitando diante da verdade dessa proposição, afirmando a verdade desta, querendo que ela seja verdade etc).

Se todo pensamento tem uma estrutura proposicional, e se os gêneros de pensamento se dividem em idéias, isto é, na exibição de uma situação possível ao espírito, que exibem, portanto, conteúdos proposicionais e idéias acrescidas de uma atitude mental, ou seja, um conteúdo proposicional acrescido de uma atitude proposicional, então o fato de se ter ou não uma linguagem é evidência suficiente para se afirmar a existência ou não de pensamento. Pois, nesse sentido, seriam necessárias construções conceituais tanto para a expressão de um conteúdo proposicional (uma idéia), quanto para a distinção e determinação precisa, dentre as infinitas atitudes mentais possíveis, de qual atitude estaria envolvida em um determinado pensamento.

Até esse ponto, portanto, é razoável afirmar que os animais não-humanos são semelhantes às máquinas porque não pensam, já que, não sendo capazes de falar, não seriam capazes de distinguir aquilo sobre o que estariam pensando, nem tampouco o ato mental em particular envolvido no momento em que pensassem. Entretanto, não se pode ainda dizer que os animais não-humanos não têm experiências sensoriais. Isto é, pode-se até aqui afirmar com Descartes que os animais não são capazes de ter operações mentais cujos objetos podem ser expressos em discurso e que, portanto, não pensam. Mas mesmo a escolástica concederia isso a Descartes. Com efeito, segundo essa tradição, os animais não pensam (são destituídos da parte racional da alma), mas têm experiências sensoriais na medida em que são dotados da parte sensitiva da alma. Para escapar de recair nessa visão escolástica e, portanto, para sustentar que os animais, além de não pensarem, são como máquinas, não têm experiência sensorial, Descartes teria que mostrar ainda mais: que todo o comportamento animal não-humano pode ser explicado em termos fisiológicos, sem recurso a qualquer tipo de consciência.

Com base nesse fato de que negar pensamento aos animais não implica necessariamente que todo o comportamento animal possa ser explicado por movimentos puramente materiais, conjugado a algumas passagens nos textos de Descartes, alguns intérpretes (Cottingham, por exemplo) ${ }^{4}$ preferem a 
alternativa interpretativa segundo a qual Descartes não estaria comprometido com a tese bizarra de que os animais não têm sensações, mas apenas com a tese de que os animais não pensam. Com efeito, Descartes algumas vezes afirma explicitamente que os animais não-humanos expressam paixões. Mas note-se que, sempre que o faz, tem o cuidado de deixar claro que o que está sendo entendido como paixão é simplesmente um movimento natural corpóreo. Assim, por exemplo, na mesma carta a Henry More, na qual ele declara que o uso da linguagem é o que distingue o homem do animal não-humano, Descartes afirma “... todos eles [os animais não-humanos] nos fazem compreender claramente seus movimentos naturais de raiva, de medo, de fome, e outros do mesmo tipo $^{5}$ ". (Note-se que Descartes qualifica de movimento natural a raiva, o medo etc.). Nesse mesmo sentido, em carta ao Marquês de Newcastle, Descartes diz: "[...] todas as coisas que os cachorros, os cavalos e os macacos são ensinados a fazer são meramente expressões de seu medo, sua esperança ou sua alegria", mas note-se que ele em seguida acrescenta: "e, conseqüentemente, eles podem fazer essas coisas sem qualquer pensamento [...]"6. Mais ainda, nos Princípios, livro IV, p. 190, ao tratar das sensações e sentimentos do homem, Descartes faz uma distinção entre o que seria para o composto corpo e alma uma "alegria espiritual", que seria o tipo de pensamento puro que Deus e os anjos sentiriam, uma apreensão puramente intelectual e uma "alegria animal", que seria o sentimento de alegria. Em suas palavras,

[...] quando ouvimos uma boa notícia, é antes de tudo a mente que faz um juízo sobre isso e se regozija com essa alegria intelectual que ocorre sem qualquer movimento corpóreo [...]. Porém, mais tarde, quando a boa notícia é exibida na imaginação, os espíritos animais [...] causam um movimento no cérebro que produz na mente uma sensação de alegria animal.

Essa alegria animal é, entretanto, explicada apenas em termos de movimentos corporais. Ainda em suas palavras:

Os nervos que vão para o estômago, esôfago, garganta e outras partes internas [...] produzem um tipo de sensação interna que é chamada de apetite natural (por exemplo, fome e sede). Os nervos que vão para o coração e áreas em volta [...] produzem um outro tipo de sensação interna que inclui todas as paixões e emoções da mente como a alegria, a tristeza, o amor, o ódio, etc [...].

É nesse sentido, portanto, que Descartes afirma admitir sensações ou mesmo alma nos animais: trata-se de movimentos corporais que não constituem,

5 Grifo nosso.

6 Carta ao marques de Newcastle de 23 de novembro de 1646 (Tratado sobre o homem, AT XI). 
entretanto, uma consciência sensorial. Em sua resposta às Sextas objeções, Descartes admite, ainda, "que os animais não-humanos têm o que normalmente se chama de 'vida', uma alma corpórea e sensação orgânica" e, explica, na carta a Henry More, que "alma corpórea [...] é puramente mecânica e corpórea, e depende apenas da força dos espíritos animais e da estrutura de nossos órgãos". Assim como nos textos citados, Descartes em muitos outros se refere às paixões dos animais não-humanos. Entretanto, o que parece manifesto é que essas paixões que ele não nega aos animais não são paixões conscientes e, portanto, não são paixões no sentido estrito, mas apenas movimentos mecânicos. Mas, se é assim, tem-se que admitir que o que Descartes entende por experiência sensorial propriamente dita é um pensamento conceitual, mesmo que confuso, acerca de estados (movimentos) do corpo. Descartes, portanto, parece tomar como experiência sensorial propriamente dita a idéia, embora confusa, de um movimento corpóreo, em oposição a um sentimento desprovido de qualquer determinação conceitual. Parece, assim, ser nesse sentido que se deve compreender sua resposta a Hobbes quando afirma: "é evidente que ver um leão e ao mesmo tempo ter medo dele é diferente de simplesmente vêlo. E ver um homem correr é diferente de afirmar em silêncio para si mesmo que se vê". Isto é, a julgar pelo argumento da linguagem, o que Descartes quereria dizer é que a experiência sensorial de ver um leão consiste em ter a idéia de que se vê um leão (que pode ser parafraseada por "me parece que ou penso que vejo um leão" e, portanto, é uma construção conceitual, ainda que confusa, que exibe uma situação possível — estar diante de mim um leão) e é diferente de se ter essa idéia e acrescentar-se a ela uma atitude proposicional (por exemplo, a de ter medo de que esse leão me ataque). Do mesmo modo, a experiência sensorial de ver um homem correr consiste em ter uma idéia, ainda que esta possa ser confusa, de que está diante de mim um homem correndo, o que é diferente de afirmar em meu espírito a verdade dessa situação, isto é, afirmar que é verdade que está diante de mim um homem correndo. Sendo assim, parece que para Descartes o aspecto consciente de toda experiência sensorial é uma aplicação, mesmo que confusa, quando não determinada, do poder do pensamento conceitual.

Até aqui, portanto, Descartes teria argumentado que mesmo admitindo que os animais têm impulsos de raiva, medo, fome etc, essas são sensações apenas "na medida em que dependem de um órgão corpóreo" e, por isso mesmo, podem ser explicadas apenas com recurso a movimentos materiais. Nesse sentido, a sensação que caberia aos animais não-humanos seria, para retomar a classificação cartesiana de graus de sensação, a sensação no primeiro grau, e é apenas esse grau da sensação que Descartes admite ser comum aos homens e 
animais não-humanos. Sendo assim, Descartes teria, com o argumento da hipótese do homem-máquina, mostrado que não só os animais não-humanos podem ser como máquinas na medida em que não pensam discursivamente, mas podem ser totalmente como máquinas à medida que mesmo seus impulsos de raiva, medo, sede etc, por não envolverem uma idéia, ainda que confusa, podem ser explicados sem apelo ao pensamento, e, por isso mesmo, não são propriamente sensações.

Restaria, então, o passo final da argumentação cartesiana em favor da tese de que os animais são como máquinas e, por isso mesmo, todo seu comportamento não só pode ser explicado por meios puramente fisiológicos, isto é, sem recurso à razão mas, mais que isso, necessariamente devem ser assim analisados. É ainda no Tratado sobre o homem que aparece esse último passo da argumentação. Ao explicar o comportamento do homem-máquina, Descartes argumenta, como vimos, que o recurso às partes sensitiva e vegetativa da alma é desnecessário e acrescenta, sem, entretanto, argumentar, o princípio metafísico segundo o qual "a natureza sempre age pelos meios mais simples e mais fáceis". Sendo assim, se para explicar as paixões de animais não-humanos é desnecessário o recurso a um aparato complexo (tal como uma alma vegetativa e sensitiva embora não racional), então esse aparato é supérfluo e, dada a simplicidade da natureza, não existe. Donde a conclusão final: os animais não têm razão e nem, por conseguinte, experiências sensoriais.

Desse esboço da argumentação cartesiana em favor da tese de que os animais, diferentemente dos homens, não têm sensações, um problema parece surgir. Se é em virtude do fato de que é desnecessário o apelo ao pensamento ou à consciência para explicar o comportamento animal não-humano que Descartes pode afirmar que estes não possuem pensamento ou experiência sensorial, por que o mesmo não se aplicaria aos humanos em geral? Isto é, parece que o que faz com que Descartes admita que os animais têm ao menos aquilo que ele chama de sensação orgânica é o fato de não se poder negar que eles têm expressões naturais e comportamentos, semelhantes aos dos homens, quando estes supostamente têm sensações. Por exemplo, os animais choram em determinadas situações e não em outras, buscam comida e não água quando algo acontece em seu corpo, fogem do perigo, mas não do que lhes agrada etc. Mas, conclui Descartes, essas expressões podem ser (e, dada a simplicidade da natureza, são, efetivamente) explicadas pelo projeto de um ser perfeitíssimo, segundo o qual sempre que certas modificações ocorressem nesse corpo, este responderia com certas expressões e comportamentos, e não porque tem experiência sensorial, já que esta suporia um pensamento conceitual, mesmo que confuso, isto é, suporia ao menos uma idéia confusa de uma sensação. $\mathrm{O}$ 
que os animais não-humanos exprimiriam através dessas expressões naturais seriam apenas os movimentos dos nervos nos corpos que podem, portanto, ser explicados em termos puramente fisiológicos.

Mas se é assim, por que o mesmo não poderia ocorrer com os homens? Se é possível explicar todo o comportamento do animal não-humano, inclusive suas expressões naturais, como exprimindo apenas movimentos corporais, por que não explicar as expressões naturais dos homens do mesmo modo? Se, mais ainda, as sensações não são propriamente um modo do pensamento na medida em que, como afirma Descartes a respeito da imaginação (e, por conseguinte, das sensações), “ainda que não a possuísse de modo algum, está fora de dúvida que eu permaneceria o mesmo [...]", por que poderia Descartes insistir que nos homens, embora se possa, como nos animais, explicar em termos puramente fisiológicos as manifestações de suas paixões, essa explicação não é a legítima? Por que recorrer a um amálgama entre dois elementos incompatíveis (corpo e a alma) que, a princípio, seria tão problemático quanto o recurso a entidades como formas substanciais que, por isso mesmo, Descartes pretende ter eliminado em sua explicação do comportamento animal nãohumano? Se, como afirma o filósofo, nos Princípios, parte IV, 201, explicar fisiologicamente as coisas é "[...] muito melhor do que explicar as coisas inventando todo tipo de objeto estranho [...] tais como [...] formas substanciais, e toda a gama de qualidades que as pessoas habitualmente introduzem, todas elas mais difíceis de compreender do que aquilo que elas devem explicar", então por que explicar as sensações humanas com recurso a uma unidade misteriosa e mesmo contraditória entre duas substâncias que têm como propriedade a exclusão recíproca, no lugar de explicar essas "sensações" humanas segundo o modelo homem-máquina, ou animal não-humano?

Com relação ao eu, afirma Descartes na Sexta meditação, do fato de que sinto sede (me parece que sinto sede), concluo que meu corpo está unido à minha alma de tal forma que o que ocorre nele é causa de uma ocorrência na minha alma. Em suas palavras, "a natureza ensina, por esses sentimentos de dor, fome, sede etc, que não somente estou alojado em meu corpo, como um piloto em seu navio, mas, além disso, que estou conjugado muito estreitamente e de tal modo confundido e misturado que componho com ele um único todo." Isto é, sei que minha alma não está somente alojada em meu corpo como um piloto em seu navio de tal forma que, diferentemente de um anjo com corpo, por exemplo, tenho dor quando meu corpo é ferido e não apenas percebo esse ferimento, isto é, os movimentos dos nervos, pelo entendimento. Admitindo a tese cartesiana do acesso privilegiado do eu a seus próprios estados mentais, e portanto, ao que seriam suas sensações, é só por analogia que 
posso concluir que os outros homens (isto é, outras criaturas que têm linguagem e corpo) também têm sensação. Ou seja, não há nenhuma evidência a partir da qual eu possa concluir que existem outras criaturas dotadas de sensação ou, em outras palavras, criaturas que não só têm alma, mas cuja alma está substancialmente conjugada a seu corpo. O que posso garantir, entretanto, com relação aos outros homens, talvez seja apenas que eles expressam sensações do primeiro grau, como os animais não-humanos. Se os animais não-humanos têm as mesmas expressões naturais que os humanos e estas exprimem apenas movimentos fisiológicos, sem qualquer consciência sensorial, por que atribuir consciência sensorial aos outros humanos se tudo que eles têm como manifestação espontânea de que sentem são exatamente suas expressões naturais como as dos animais? Em outras palavras, por que para o caso dos outros homens as expressões naturais bastam para que se atribuam a eles sensações?

Parece plausível, portanto, que, se os animais podem ser máquinas perfeitíssimas criadas pelo melhor dos artesãos, então o corpo de todos os outros homens, que não eu, pode, do mesmo modo, ter sido criado. Se porque assim seria mais simples, é porque assim o é para o caso dos animais, então, o mesmo se poderia afirmar para o caso dos homens. O que implicaria que Descartes não só defende a tese bizarra de que os animais não-humanos não têm sensações, mas também a tese, ainda mais bizarra, de que os outros homens, que não eu, tampouco sentem.

Nesse sentido, o que Descartes poderia afirmar é: 1) que os animais não pensam, já que são incapazes de usar uma linguagem; 2) que os homens, ao contrário, pensam, já que usam linguagem, isto é, pensam, por exemplo, que têm uma certa sensação, mas isso é apenas uma construção conceitual e, por isso mesmo, objeto do entendimento, da alma, pura; pensam em suas sensações, portanto, do mesmo modo que um piloto percebe, pela vista, algum rompimento em seu navio; 3) eu tenho sensações na medida em que sou imediatamente consciente delas; 4) nem os animais nem os outros homens sentem, no sentido forte, na medida em que a natureza dispensa qualquer aparato mais complexo do que o necessário: tanto nos homens quanto nos animais não-humanos as manifestações de experiências sensoriais podem ser explicadas em termos puramente fisiológicos, donde dependerem apenas do corpo, a menos que o fato de que Descartes não tenha repetido a tese da simplicidade dos meios de a natureza agir signifique que não tenha mantido essa tese. Mas, se é assim, Descartes não poderia se pronunciar acerca da atribuição ou não de sensações a animais em geral (não-humanos e humanos). 


\section{Referências}

ADAM, C. ; Tannery, P. (Ed.). Oeuvres de Descartes. Paris: Vrin/CNRS, 1964-1976. $12 \mathrm{v}$.

COTTINGHAM, J., A Brute to the Brutes? Descartes' Treatment of Animals. In: MOYAL, G. (Ed.). René Descartes Critical Assessments. London/New York: Routledge, 1991.

DESCARTES, R. Descartes Philosophical Letters. Trad. A. Kenny. Oxford: Oxford University Press, 1970.

MARION, J.-L. (Ed.). Règles utiles et claires pour la direction de l'esprit. Trad. J-L. Marion. The Hague: Nijhoff, 1977.

STOOTHOFF, R.; Murdoch, D. (Ed.). The Philosophical Writings of Descartes. Cambridge: Cambridge University press, 1985. 3 v. 